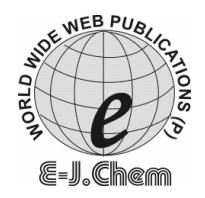

http://www.e-journals.net
ISSN: 0973-4945; CODEN ECJHAO

E-Journal of Chemistry 2009, 6(2), 594-600

\title{
RP-HPLC Method for the Estimation of Donepezil Hydrochloride Dosage Form
}

\author{
TUSHAR G. BAROT* and P. K. PATEL \\ *Department of Chemistry, \\ M.G.Science Institute, Ahmedabad Gujarat, India. \\ Department of Chemistry, \\ M.G.Science Institute, Ahmedabad Gujarat, India. \\ drtushar8055@gmail.com
}

Received 9 September 2008; Accepted 1 November 2008

\begin{abstract}
A simple and accurate methods to determine donepezil, in tablet dosage form, were developed and validated using liquid chromatography (LC). The LC separation was achieved on a Inertsil C8-3, $25 \mathrm{~cm} \times 4.6-\mathrm{mm}, 5 \mu$ in the isocratic mode using buffer : methanol : triethylamine (550:450:5)v/v, adjusted to $\mathrm{pH} 2.50 \pm 0.05$ with orthophosphoric acid, as the mobile phase at a flow rate of $1.0 \mathrm{~mL} / \mathrm{min}$. The methods were performed at $271 \mathrm{~nm}$. In LC method, quantification was achieved with PDA detection over the concentration range of $20-60 \mu \mathrm{g} / \mathrm{mL}$ with mean recovery of $100.18 \pm 0.75 \%$. The method was validated by determining its sensitivity, accuracy and precision. The proposed method is simple, fast, accurate and precise and hence can be applied for routine quality control of donepezil $\mathrm{HCl}$ in bulk and tablet dosage form.
\end{abstract}

Keywords: Donepezil HCl, RP-HPLC, Estimation and Tablets.

\section{Introduction}

Donepezil $\mathrm{HCl}$ ARICEPT® (donepezil hydrochloride) is a known chemically as ( \pm )-2,3-dihydro5,6-dimethoxy-2-[[1-(phenylmethyl)-4-piperidinyl]methyl]-1 $H$-inden-1-one hydrochloride (also known as E2020 or Aricept ${ }^{\circledR}$. It has an empirical formula of $\mathrm{C}_{24} \mathrm{H}_{29} \mathrm{NO}_{3} \mathrm{HCl}$ and molecular weight of 415.96. The registered trademark of Eisai Co. Ltd, Tokyo, Japan) is a piperidine based inhibitor of the enzyme acetylcholinesterase (AChE). It has recently been approved for marketing in the USA, Canada and several EU member states, including the UK, for the symptomatic treatment of mild to moderate Alzheimer's disease. In vitro studies have demonstrated that donepezil has a significantly greater degree of selectivity for AChE in the central nervous system (CNS) than for butyrylcholinesterase (BuChE) in the periphery. Clinical trials undertaken in the USA and Europe have demonstrated that donepezil 
(5 mg or $10 \mathrm{mg}$, once daily) significantly improves cognitive and global function in patients with Alzheimer's disease. Furthermore, these studies have shown that donepezil is well tolerated and is not associated with the hepatotoxicity that is commonly seen with acridinebased cholinesterase inhibitors, such as tacrine. Phase I studies conducted in the USA have demonstrated that donepezil pharmacokinetics are linear and dose proportional and are characterized by slow plasma clearance and a long half-life $(70-80 \mathrm{~h})$. Although donepezil is metabolized primarily by the P-450 isoenzyme CYP-3A4 and to a lesser extent by CYP2D6, compromised hepatic function does not significantly affect its pharmacokinetic profile. Donepezil hydrochloride is a white crystalline powder and is freely soluble in chlorofom, soluble in water and in glacial acetic acid, slightly soluble in ethanol and in acetonitrile and practically insoluble in ethyl acetate and in $n$-hexane.

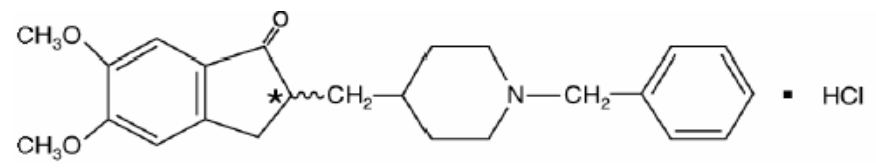

Since its recognition as a broncodilator almost 50 years ago, theophylline, a methylxanthine alkaloid, has played an important role in the management of both acute and chronic reversible airway obstruction, in particular asthma and chronic bronchitis. However, it has a narrow safety window, which, along with its variability in disposition, makes dosing difficult to predict and toxicity difficult to prevent. Symptoms of toxicity include tachycardia, severe restlessness, agitation, nausea and vomiting, particularly at high blood concentrations.

The physical status of a patient can greatly alter theophylline metabolism and/or elimination, resulting in toxic plasma levels. Several disease states, as well as advanced age, smoking and obesity, have been shown to influence the pharmacokinetics of theophylline Previous reports have also demonstrated that the half-life of theophylline is prolonged, and plasma clearance decreased, in patients with liver disease, acute pulmonary oedema and congestive heart failure.

Theophylline is prone to clinically significant interactions with other drugs. For instance, the clearance of theophylline is increased substantially during the concomitant administration of phenytoin. Rifampin and oral contraceptives produce smaller but appreciable increases in theophylline clearance, whereas cimetidine and erythromycin have been reported to reduce the clearance of theophylline.

\section{Experimental}

Donepezil Tablets (ARICEPT 1; 5 mg/tablet, ARICEPT 2; $5 \mathrm{mg} / \mathrm{tablet}$ ) of Zydus Cadila Ltd., (Ahmedabad, India) were purchased from local market. HPLC grade methanol were purchased from SD fine chemical (Ahmedabad, India). The water for LC was prepared by triple glass distillation and filtered through nylon $0.45 \mu \mathrm{m}-47 \mathrm{~mm}$ membrane filter (Gelman laboratory, Mumbai, India). Potassium dihydrogen orthophosphate, orthophosphoric acid and triethylamine were procured from SD fine chemical (Ahmedabad, India) and were of analytical grade.

\section{Instrument}

High Performance Liquid Chromatograph, Waters Alliance HPLC 2996, instrument equipped with PDA detector 2996, Auto injector of $200 \mu \mathrm{L}$ loop was used with Empower software. A Sartorius CP224S (Gottingen, Germany) analytical balance, and an ultra sonic cleaner (Frontline FS 4, Mumbai, India) were also used. 


\section{Chromatographic conditions}

Chromatographic separation were achieved using a Inertsil C8-3, 25-cm x 4.6-mm, $5 \mu$ GL sciences Japan, in the isocratic mode using buffer: methanol: Triethylamine (550:450: 5)v/v, adjusted to $\mathrm{pH} 2.50 \pm 0.05$ with orthophosphoric acid, as the mobile phase at a flow rate of $1.0 \mathrm{~mL} / \mathrm{min}$. The mobile phase was filtered through nylon $0.45 \mu \mathrm{m}-47 \mathrm{~mm}$ membrane filters and was degassed before use. The elution was monitored at $271 \mathrm{~nm}$ and the injection volume was $20 \mu \mathrm{L}$. and column oven temperature $50^{\circ} \mathrm{C}$.

\section{Preparation of buffer}

$2.75 \mathrm{~g}$ of potassium dihydrogen orthophosphate was transferred into $1000 \mathrm{~mL}$ water. Sonicated to dissolve and then adjusted the $\mathrm{pH}$ to $2.50 \pm 0.05$ by adding orthophosphoric acid. Then filtered through nylon $0.45 \mu \mathrm{m}-47 \mathrm{~mm}$ membrane filter and degassed prior to use.

\section{Preparation of donepezil standard solutions}

Accurately weighed $50.0 \mathrm{mg}$ of donepezil hydrochloride was transferred to a $250 \mathrm{~mL}$ volumetric flask, add about $150 \mathrm{~mL}$ of mobile phase and sonicated to dissolve, diluted up to the mark with mobile phase and mixed. Further $5 \mathrm{~mL}$ of the resulting solution was diluted to $25 \mathrm{~mL}$ with mobile phase.

\section{Preparation of donepezil sample solutions}

Accurately not less than 10 tablets were weighed and crushed to fine power. Powdered tablets were accurately weighed (20 mg of donepezil hydrochloride) and transferred into a $100 \mathrm{~mL}$ volumetric flask. About $60 \mathrm{~mL}$ of mobile phase was added and sonicated for $10 \mathrm{~min}$ with intermittent shaking. Further diluted up to the mark with mobile phase and mixed. The resulting solution was centrifuged at $3000 \mathrm{rpm}$ for $15 \mathrm{~min}$. Further $5 \mathrm{~mL}$ of the clear supernatant solution was diluted to $25 \mathrm{~mL}$ with mobile phase.

\section{Method validation}

\section{Specificity}

(a) No interference from excipients

This was demonstrated by injecting blank, placebo, sample and standard prepared from the same. There is no peak at the retention time of donepezil. There by indicating that there was no interference form blank and excipients.

(b) No interference from degradation products.

This was demonstrated by carrying out forced degradation of sample blend with $5 \mathrm{~N}$ $\mathrm{HCl}, 5 \mathrm{~N} \mathrm{NaOH}, 30 \% \mathrm{H}_{2} \mathrm{O}_{2}$, heating in water bath at $80{ }^{\circ} \mathrm{C}$ and keeping under UV light at $254 \mathrm{~nm}$ for $24 \mathrm{~h}$. Prepared samples as per test preparation was injected into HPLC with photodiode array detector. In each case, purity factor for donepezil peak was determined to examine interference from degradation products.

\section{Acid degradation}

Accurately weighed quantity of powdered tablets equivalent to $20 \mathrm{mg}$ of donepezil hydrochloride was transferred to a $100 \mathrm{~mL}$ volumetric flask. $10 \mathrm{~mL}$ of mobile phase was added and sonicated for $10 \mathrm{~min} .5 \mathrm{~mL}$ of $5 \mathrm{~N} \mathrm{HCl}$ was added and heated in water bath at $80{ }^{\circ} \mathrm{C}$ for $30 \mathrm{~min}$. Cooled and neutralized with $5 \mathrm{~mL}$ of $5 \mathrm{~N} \mathrm{NaOH}$, volume was made up with mobile phase. This solution was injected into the HPLC system. The purity angle was less than purity threshold for donepezil peak. 


\section{Alkali degradation}

Accurately weighed quantity of powdered tablets equivalent to $20 \mathrm{mg}$ of donepezil hydrochloride was transferred to a $100 \mathrm{~mL}$ volumetric flask. $10 \mathrm{~mL}$ of mobile phase was added and sonicated for $10 \mathrm{~min} .5 \mathrm{~mL}$ of $5 \mathrm{~N} \mathrm{NaOH}$ was added and heated in water bath at $50{ }^{\circ} \mathrm{C}$ for $30 \mathrm{~min}$. Cooled and neutralized with $5 \mathrm{~mL}$ of $5 \mathrm{~N} \mathrm{HCl}$, volume was made up with mobile phase. The resulting solution was centrifuged at $3000 \mathrm{rpm}$ for $15 \mathrm{~min} .5 \mathrm{~mL}$ of the supernatant solution was diluted to $25 \mathrm{~mL}$ and volume was made with mobile phase. This solution was injected into the HPLC system. The purity angle was less than purity threshold for donepezil peak.

\section{Peroxide degradation}

Accurately weighed quantity of powdered tablets equivalent to $20 \mathrm{mg}$ of donepezil hydrochloride was transferred to a $100 \mathrm{~mL}$ volumetric flask. $10 \mathrm{~mL}$ of mobile phase was added and sonicated for $10 \mathrm{~min} .2 \mathrm{~mL}$ of $30 \% \mathrm{H}_{2} \mathrm{O}_{2}$ was added and heated in water bath at $80{ }^{\circ} \mathrm{C}$ for $30 \mathrm{~min}$. Cooled and neutralized with $5 \mathrm{~mL}$ of $5 \mathrm{~N} \mathrm{HCl}$, volume was made up with mobile phase. The resulting solution was centrifuged at $3000 \mathrm{rpm}$ for $15 \mathrm{~min} .5 \mathrm{~mL}$ of the supernatant solution was diluted to $25 \mathrm{~mL}$ and volume was made with mobile phase. This solution was injected into the HPLC system. The purity angle was less than purity threshold for donepezil peak.

\section{UV Degradation}

Accurately weighed quantity of powdered tablets equivalent to $20 \mathrm{mg}$ of donepezil hydrochloride (Previously kept in UV light for $24 \mathrm{~h}$ ) was transferred to a $100 \mathrm{~mL}$ volumetric flask. $60 \mathrm{~mL}$ of mobile phase was added and sonicated for $10 \mathrm{~min}$. The volume was made up with mobile phase. The resulting solution was centrifuged at $3000 \mathrm{rpm}$ for $15 \mathrm{~min} .5 \mathrm{~mL}$ of the supernatant solution was diluted to $25 \mathrm{~mL}$ and volume was made with mobile phase. This solution was injected into the HPLC system. The purity angle was less than purity threshold for donepezil peak.

\section{Thermal degradation}

Accurately weighed quantity of powdered tablets equivalent to $20 \mathrm{mg}$ of donepezil hydrochloride was transferred to a $100 \mathrm{~mL}$ volumetric flask. $20 \mathrm{~mL}$ of mobile phase was added and sonicated for $10 \mathrm{~min}$. Then heated in a water bath at $80^{\circ} \mathrm{C}$ for $30 \mathrm{~min}$. Cooled and volume was made with mobile phase, The resulting solution was centrifuged at $3000 \mathrm{rpm}$ for $15 \mathrm{~min} .5 \mathrm{~mL}$ of the supernatant solution was diluted to $25 \mathrm{~mL}$ and volume was made with mobile phase. This solution was injected into the HPLC system. The purity angle was less than purity threshold for donepezil peak.

\section{Calibration curve (Linearity) LC method}

The Calibration curves were plotted over the concentration range of $20-60 \mu \mathrm{g} / \mathrm{mL}$. Accurately measured working standard solutions of donepezil $(2.5,4.0,5.0,6.0$ and $7.5 \mathrm{~mL})$ were transferred in to a series of $25 \mathrm{~mL}$ volumetric flasks and diluted to the mark with diluent. $20 \mu \mathrm{L}$ of each solution were injected under the operating chromatographic conditions as described above. Calibration curves were constructed by plotting peak areas vs. concentrations of donepezil, and the regression equations were calculated. Each reading was average of three determinations.

\section{Accuracy (\% Recovery)}

The accuracy of the methods was determined by calculating recoveries of donepezil by the standard additions method. Known amount of standard solution of donepezil (50\%, 100\% and $150 \%$ of label claim) for LC method, were added to a pre-quantified sample solution of tablet dosage form. The amount of donepezil was estimated by applying these values to the regression equation of calibration curve. 


\section{Method precision (Repeatability)}

The precision was checked by repeatedly injecting $(\mathrm{n}=6)$ standard solution of TAD $(1.5 \mu \mathrm{g} /$ $\mathrm{mL}$ ) for $\mathrm{LC}$ method.

\section{Limit of detection and limit of quantification}

The limit of detection (LOD) and the limit of quantification (LOQ) of the drug were calculated using the following equations as per International Conference on Harmonization (ICH) guidelines (41).

$$
\begin{aligned}
& \mathrm{LOD}=3.3 \times \sigma / \mathrm{S} \\
& \mathrm{LOQ}=10 \times \sigma / \mathrm{S}
\end{aligned}
$$

Where $\sigma=$ the standard deviation of the response; $S=$ the slope of the regression line

\section{Analysis of donepezil tablet dosage form}

Tablets containing donepezil were purchased from local market. The responses of the tablet dosage form were measured at $271 \mathrm{~nm}$ for quantification of donepezil by LC. The amount of donepezil present in sample solution was determined by fitting the responses into the regression equation of donepezil.

\section{Robustness}

Three sample solutions of same lot of donepezil shall be prepared as per method and analyzed using different chromatographic condition as below.

(1) Chang in flow $( \pm 0.2 \mathrm{~mL} / \mathrm{min})$

(2) Chang in organic composition of mobile phase $( \pm 5.0 \%)$.

(3) Chang in $\mathrm{pH}$ of mobile phase by \pm 0.2 unit.

(4) Change in temp of column by \pm 0.2 unit.

\section{Stability in analytical solution}

This was evaluated by injecting initially a freshly prepared donepezil standard solution and sample solution at different time intervals. The peak response date is given below (Table 1)

Table 1. Peak response data.

\begin{tabular}{ccccc}
\hline Time,h & \multicolumn{2}{c}{ Ratio of peak response } & $\begin{array}{r}\% \text { Deviation From Mean Initial } \\
\text { Area Counts }\end{array}$ \\
\cline { 2 - 5 } & Standard & Sample & Standard & Sample \\
\hline Initial & 1302095 & 1247814 & 0.0 & 0.0 \\
12 & 1306036 & 1255382 & 0.3 & 0.6 \\
24 & 1308838 & 1256448 & 0.5 & 0.7 \\
36 & 1311178 & 1263092 & 0.7 & 1.2 \\
48 & 1316012 & 1265641 & 1.1 & 1.4 \\
\hline
\end{tabular}

\section{Results and Discussion}

LC method

To optimize the LC parameters, several mobile phase compositions were tried. A satisfactory separation and good peak symmetry for donepezil was obtained with mobile phase consisting of buffer: methanol: triethylamine (550: 450: 5) v/v, adjusted to $\mathrm{pH} 2.50 \pm$ 0.05 with orthophosphoric acid, as the mobile phase at a flow rate of $1.0 \mathrm{~mL} / \mathrm{min}$. The elution was monitored at $271 \mathrm{~nm}$. Better resolution of the peaks with clear base line separation was found (Figure 1). 


\section{Validation of the proposed methods}

\section{Linearity}

Linear correlation was obtained between peak area and concentration of donepezil in the range of $20-60 \mu \mathrm{g} / \mathrm{mL}$ for LC method. The linearity of the calibration curves was validated by the value of correlation coefficients of the regression $(r=0.9999)$. The regression analysis of the calibration curves is shown in Table 2.

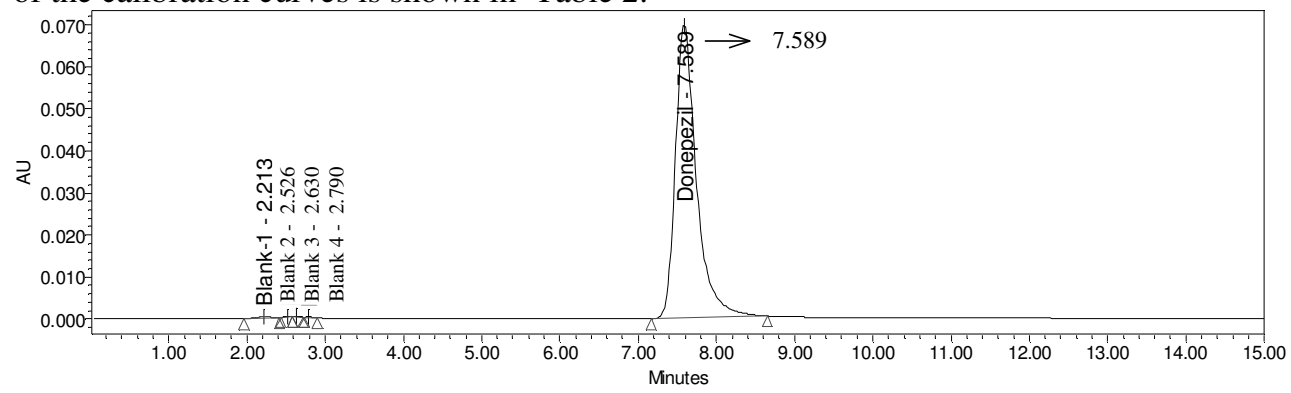

Figure 1. System precision chromatogram.

Table 2. Regression analysis of the calibration curves for donepezil hydrochloride by the proposed LC method.

\begin{tabular}{lc}
\hline Parameter & LC method \\
\hline Linearity range, $\mu \mathrm{g} / \mathrm{mL}$ & $20.8-60.84$ \\
Correlation coefficient, $\mathrm{r}$ & 0.9996 \\
\hline
\end{tabular}

Accuracy (\% Recovery)

The recovery study was carried out by the standard addition method. The percent mean recoveries obtained were $100.18 \pm 0.75 \%$ (Table 3 ) which was satisfactory. Repeatability was evaluated in terms of percentage relative standard deviation (\%RSD), which was found to be $1.72 \%$. The method is also found to be robust as no change was found in results after changing the chromatographic conditions. The system suitability test parameters are listed in Table 4.

Table 3. Summary of validation parameters for donepezil hydrochloride by the proposed LC method.

\begin{tabular}{lc}
\hline Parameter & LC method \\
\hline $\mathrm{LOD}^{\mathrm{a}}, \mu \mathrm{g} / \mathrm{mL}$ & 0.04 \\
$\mathrm{LOQ}^{\mathrm{b}}, \mu \mathrm{g} / \mathrm{mL}$ & 0.1 \\
Accuracy, $\%$ & 100.18 \\
RSD $\%$ & 1.72 \\
\hline t of detection; ${ }^{b}$ LOQ = Limit of quantification; ${ }^{c}$ RSD $=$ Relative standard deviation
\end{tabular}

${ }^{a} L O D=$ Limit of detection $;{ }^{b} L O Q=$ Limit of quantification $;{ }^{c} R S D=$ Relative standard deviation
Table 4. System suitability parameters for donepezil hydrochloride by the proposed LC method.

\begin{tabular}{lc}
\hline Parameter & donepezil $\pm \% \mathrm{RSD}^{\mathrm{a}}$ \\
\hline Retention time, $\min$ & $8.52 \pm 0.01$ \\
USP Tailing factor & $1.13 \pm 0.02$ \\
USP Plate Count & 7390.48 \\
\hline \multicolumn{2}{c}{$R S D=$ Relative Standard deviation. }
\end{tabular}

\section{Method Precision}

${ }^{a} R S D=$ Relative Standard deviation.

The percentage relative standard deviation (\% RSD) for donepezil was found to be $1.15 \%$ by LC method (Table 3 ). The RSD values indicate the proposed methods are repeatable. 


\section{Limit of detection and limit of quantification}

The LOD and LOQ of donepezil were found to be 10.000 and $0.0400 \mu \mathrm{g} / \mathrm{mL}$, respectively by LC. The validation parameters are summarized in Table 3 . The proposed method is found to be specific, as no interference of excipients was found in the estimation of donepezil in tablet dosage form.

\section{Analysis of donepezil tablet dosage form}

The proposed methods were successfully applied to determine donepezil in tablet dosage form. The results obtained for donepezil were comparable with the corresponding label claim. (Table 5).

Table 5. Analysis results for donepezil hydrochloride tablets by the proposed LC method.

\begin{tabular}{lc}
\hline Sample ID & Donepezil $\mathrm{HCl} \pm \mathrm{SD}^{\mathrm{a}}\left(\mathrm{n}^{\mathrm{b}}=5\right)$, \\
\cline { 2 - 2 } & $\mathrm{LC}$ \\
\hline S1 (ARICEPT $5 \mathrm{mg})$ & 101.32 \\
S2 (ARICEPT $5 \mathrm{mg})$ & 101.44 \\
\hline \multicolumn{2}{c}{${ }^{a}$ SD $=$ Standard deviation ${ }^{b} n=$ Number of determinations }
\end{tabular}

\section{Conclusion}

The results of the analysis of tablet dosage forms by the proposed methods are reproducible, reliable and are in good agreement with the label claim of the drug. Method were validated and found to be simple, sensitive, specific, accurate and precise. Statistical comparison of the assay results for donepezil in tablet dosage forms by method indicated no significant difference. The excipients present in the tablet dosage form did not interfere with determination of donepezil. Hence, method can be used successfully for the routine analysis of donepezil in tablet dosage form of donepezil.

\section{References}

1. Iimura Y, Mishima M and Sugimoto H, J Label Comp Radiopharm., 2006, 27, 835-839.

2. Rogers S L, Yamanishi Y and Yamatsu K, E2020-The pharmacology of a piperidine cholinesterase inhibitor. In: Becker R, Giacobini E; Editors, Cholinergic Basis for Alzheimer Therapy. Boston: Birkhäuser, 1991, 314-320.

3. Sherman K, Pharmacodynamics of oral E2020 and tacrine in humans: Novel approaches. In: Becker R, Giacobini E; Editors, Cholinergic Basis for Alzheimer Therapy. Boston: Birkhäuser, 1991, 321-328.

4. $\quad$ Rogers S L and Friedhoff L T, Dementia. 1996, 7, 293-303.

5. Rogers S L and Friedhoff L T, Eur Neuropsychopharmacol., 1998, 8, 67-75.

6. Rogers S L, Doody R S, Mohs R and Friedhoff L T, Arch Intern Med.,1998, 158,1021-1031.

7. Rogers S L, Farlow M R, Doody R S, Mohs R and Friedhoff L T, Neurology, 1998, 50, 136.

8. Watkins P B, Zimmerman H J and Knapp M J, JAMA., 1994, 271, 992-998.

9. Rogers S L, Cooper N M, Sukovaty R, Pederson J E, Lee J N and Friedhoff L T, Br J Clin Pharmacol., 1998, 46(Suppl. 1),7-12.

10. Rogers S L, Walters E J and Friedhoff L T, Neurobiol Aging.,1992, 13(Suppl.1), 125-126.

11. Rogers S L and Friedhoff L T. Clin Pharmacol Ther. 1997, 61,181 (PII-63).

12. Tiseo P J. Vargas R, Perdomo C A and Friedhoff L T, Br J Clin Pharmacol., 1998, 46(Suppl. 1), 51-55.

13. Serafin, W E. Drugs used in the treatment of asthma. In: Gilman A G, Molinoff P B, Ruddon R W, Hardman J G and Limbird L E; Editors, Goodman and Gilman's The Pharmacological Basis of Therapeutics. $9^{\text {th }}$ Ed., New York: McGraw-Hill, 1995, 659-682.

14. Griffin J P, D'Arcy P F and Speirs C J,. Manual of Adverse Drug Interactions. $4^{\text {th }}$ Ed., London, John Wright, Theophylline and derivatives, 1988, 427-439.

15. Reynolds, J E F, Martindale, The Extra Pharmacopoeia, $31^{\text {st }}$ Ed., London, The Pharmaceutical Press, 1996, 1657-1665. 


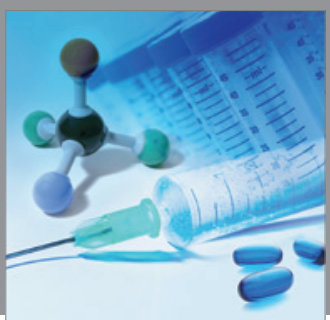

International Journal of

Medicinal Chemistry

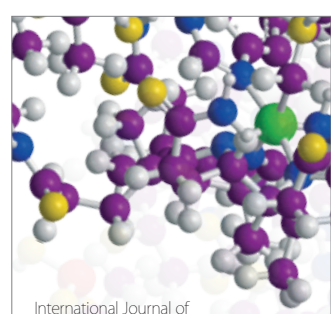

Carbohydrate Chemistry

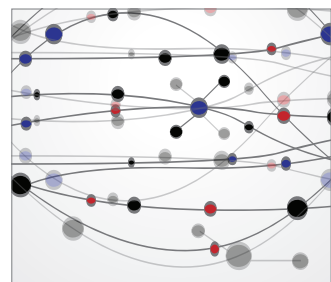

The Scientific World Journal
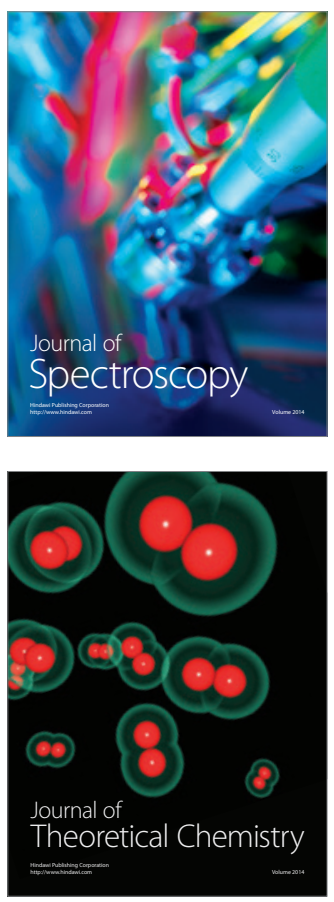
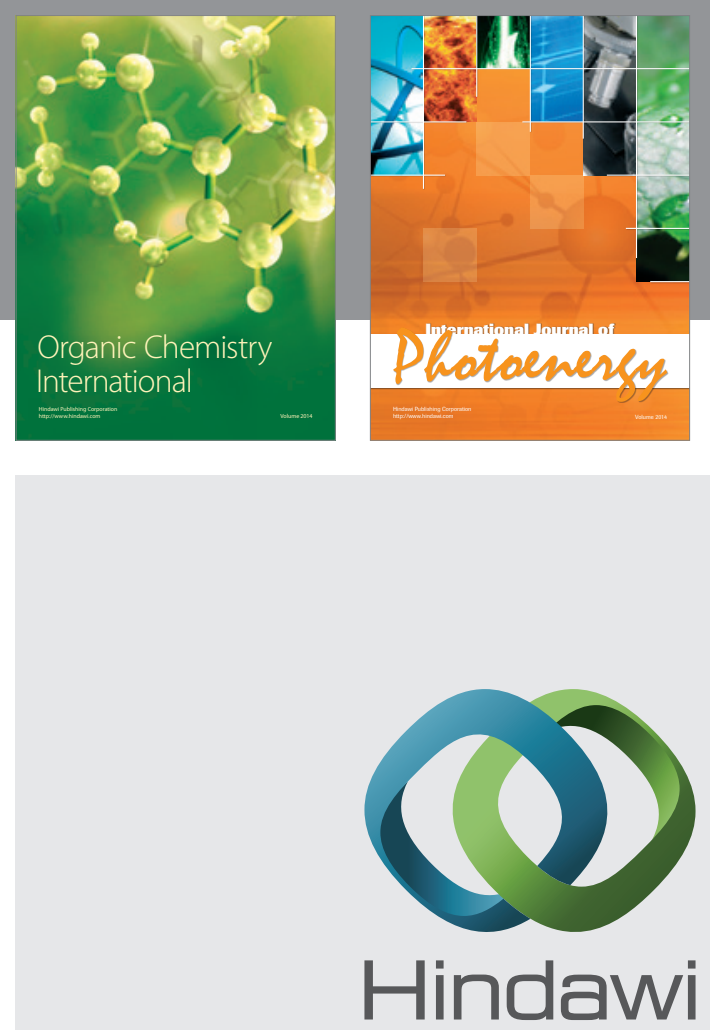

Submit your manuscripts at

http://www.hindawi.com
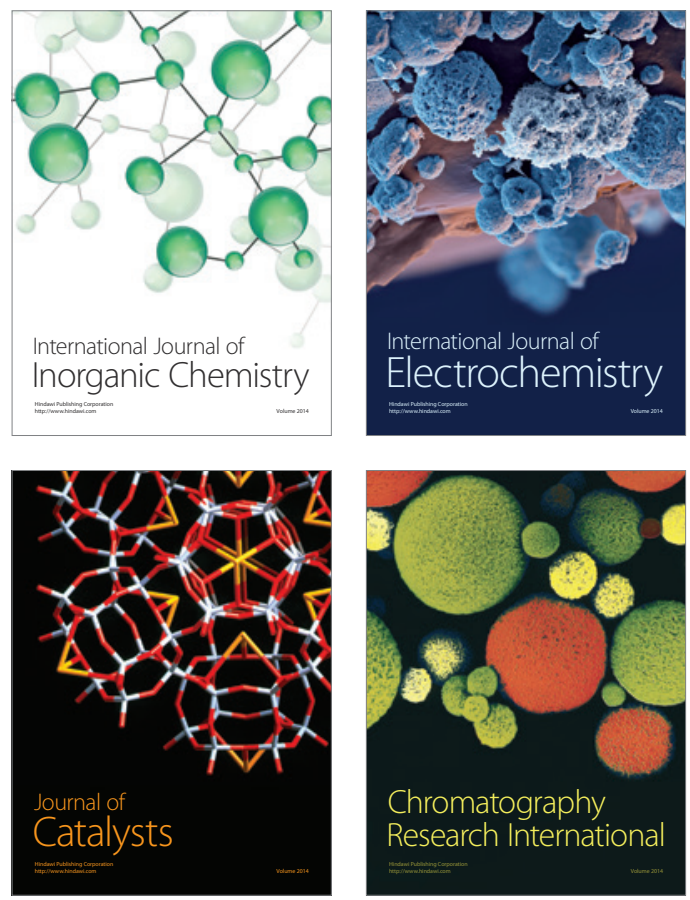
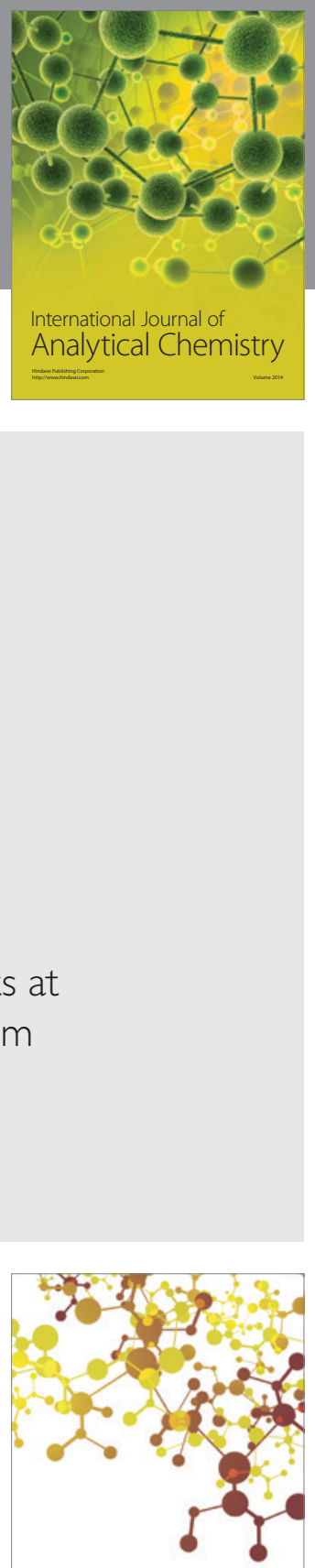

Journal of

Applied Chemistry
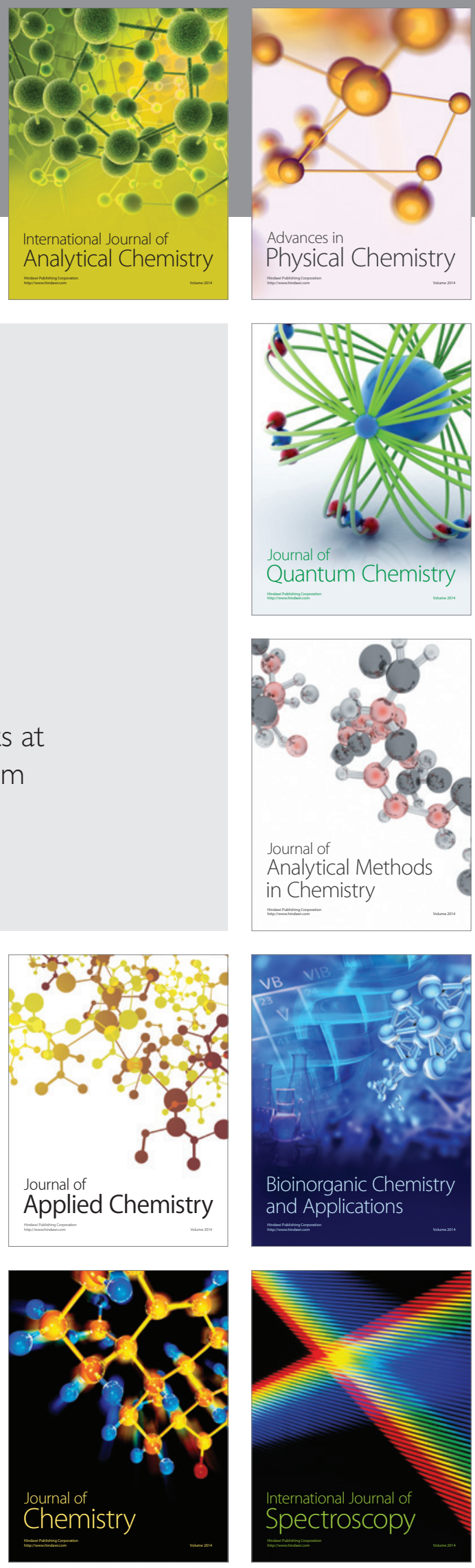